\title{
Measurement properties of the brief resilient coping scale in patients with systemic lupus erythematosus using rasch analysis
}

José-Antonio López-Pina ${ }^{1 *}$ [D, Ana-Belén Meseguer-Henarejos², Juan-José Gascón-Cánovas³, Dérlis-Julián Navarro-Villalba ${ }^{3}$, Vaughn G. Sinclair ${ }^{4}$ and Kenneth A. Wallston ${ }^{4}$

\begin{abstract}
Bacground: Resilience has been defined as the capacity or the ability to rebound from and positively adapt to significant stressors, despite experiences of significant adversity or trauma. To capture to what extent an individual copes with stress in a resilient fashion the Brief Resilient Coping Scale (BRCS) was developed. This tool was validated in people with chronic disease, such as rheumatoid arthritis using standard psychometric techniques of classical test theory, but not yet in patients with Systemic lupus erythematosus (SLE). The aim of this study was to explore the psychometric properties of the Brief Resilient Coping Scale in patients with SLE using Rasch analysis.

Method: This study used cross-sectional data. The BRCS was administered to 232 patients with systemic lupus erythematosus. The aspects analyzed were unidimensionality, local independence and differential item functioning (DIF) to construct an interpretative scale of scores with the Rasch model.

Results: Rating scale mode (RSM) showed that the four categories used in the items of the BRCS are properly ordered. The four items provided a good fit to the polytomous Rasch model. Moreover, the parameters were sufficiently separated to measure resilience in patients with SLE. BRCS is a unidimensional scale (eigenvalue $=1.843$ ) of resilience and the items were locally independent. There was no DIF between males and females in the sample. Only marginally significant differences depending on the level of education were found. The BRCS showed adequate discriminant validity between groups of scores.

Conclusions: BRCS is a suitable scale for measuring resilience in patients with SLE. This scale might be useful for clinicians to obtain information concerning the degree of resilience that each patient has, allowing individuals with low resilience to be identified who need interventions aimed at developing coping skills.
\end{abstract}

Keywords: Systemic lupus erythematosus, Resilient coping, Rasch analysis, Quality of life

\section{Background}

Systemic lupus erythematosus (SLE) is a chronic autoimmune rheumatic disease, characterized by widespread inflammation of blood vessels and connective tissue [1]. The severity of symptoms, the secondary effects of medication, its unpredictability and early onset along with the chronic evolution of the disease are stress factors that

\footnotetext{
* Correspondence: jlpina@um.es

'Department of Basic Psychology and Methodology, Faculty of Psychology, Campus of Espinardo, University of Murcia, 30100 Murcia, Spain

Full list of author information is available at the end of the article
}

provoke medium and long term psychological disorders in many sufferers [2,3]. Such orders include anxiety and depression [4-7].

These may undermine the adaptation capacity of the patient, and their ability to maintain or regain mental health. This capacity of adaptation or facing up to the disease will largely depend on the patient's psychological capacity, upon which is based the concept of resilience, which has been defined as the capacity or the ability to rebound from and positively adapt to significant 
stressors $[8,9]$, despite experiences of significant adversity or trauma [10].

Resilience was originally used in the field of physics to refer to the capacity of a material or systems to return to equilibrium after displacement, and has been adapted and developed in psychology as a theoretical construct of mental health protection, promotion and recovery processes [11]. Currently, this concept is increasingly used in the area of clinical medicine, especially, in patients with chronic diseases. Furthermore, some scientific research focuses on the role of resilience in chronic patients' adaptation to their disease [12-14].

In this sense, in certain chronic diseases, such as cancer or Parkinson's, patients with high levels of resilience have a better functional capacity, higher stability and better adaptation to their social environment. Also, the clinical symptomatology of these subjects is less severe, their pain threshold is higher, and they are less tired and are less likely to suffer from anxiety and depression, which leads to a better life quality $[15,16]$.

Because of this, evaluation of the degree of resilience is very important in subjects with chronic disease such as SLE, enabling deficit situations to be detected and improved $[17,18]$.

Resilience has been assessed mainly through selfreport measures such as the Brief Resilient Coping Scale (BCRS), a 4-item measure that has been validated for people with rheumatoid arthritis, university students and ageing persons [19-21] using standard psychometric techniques of classical test theory. However, until now this scale has not been validated for people with SLE, nor has its psychometric properties been evaluated by item response theory [22].

For this reason, the aim of the present paper is to validate the Brief Resilient Coping Scale in patients with SLE using the Rasch model, testing unidimensionality, local independence, differential item functioning (DIF), and constructing an interpretative scale of scores obtained with the fitted model.

\section{Methods}

\section{Participants and procedure}

A cross-sectional study was developed in the province of Murcia (south-eastern Spain) with patients who met the revised American College of Rheumatology classification criteria for SLE diagnosis [23]. The BRCS and EQ-5D scales were administered, from July to August 2014, by postal survey to 450 eligible subjects selected randomly from the rare disease database of the Murcia Health Service. The study conforms to the principles of the Declaration of Helsinki [24] and was approved by the Research Bioethics Committee of the University of Murcia (Spain) (ID 1204/2015; 4/11/2015).

\section{Instruments}

The Brief Resilient Coping Scale (BRCS) is a 4-item, unidimensional outcome measure designed to capture to what extent an individual copes with stress in a resilient fashion. In the original version, the items have a response format with five options, where 1 means the statement "does not describe you at all" and 5 means "it describes you very well", but in this work the number of categories was reduced to four because the central category was removed to force decision-making of patients (Appendix). The BRCS meets the minimal standard for reliability and validity of a resilience instrument. In this study, the internal consistency coefficient was 0.82 and the Spearman-Brown coefficient was 0.81 . The concurrent validity coefficient for BRCS was 0.34 with EQ-5D and 0.34 with EQ-VAS.

The EuroQol (EQ-5D) is a generic health index which comprises a five-part questionnaire (mobility, self-care, usual activities, pain/discomfort, anxiety/depression) to calculate a 'utility' or health index value between " 0 " and "1", and a visual analogue self-rating scale (EQ-VAS) which ranges from 0 (minimum score) to 100 (maximum score). The EQ-5D is a reliable and valid instrument for measure quality of life $[25,26]$.

\section{Rasch analysis}

The Rasch family of models transforms ordinal scores to interval scales (logits) [27]. For this it is necessary to specify a model according to the structure of the items in the scale. If the data fit the model specified, then independent item and ability parameters will be estimated. Also, applying the Rasch model involves evaluating the order of the item categories, fitting of the items, the separability of the parameters, and DIF. If all the analyses indicate that the scale forms a unidimensional rule of resilience, it will be possible to construct a more interpretative transformed scale.

There are two models in the Rasch family of models to estimate the location parameters of the items: the partial credit model (PCM) [28] and the rating scale model (RSM) [29]. Both models determine the parameters of the transitions between the categories of the items, but PCM allows each item to have a different unordered threshold, while RSM permits equal transitions between categories for each item. Therefore, a first evaluation of the appropriate model to explain the BRCS results involves examining whether the average score of the people who have answered each category in each item increases monotonically. A second evaluation involves comparing the fit in both models with the deviance $\left(\mathrm{G}^{2}\right)$ which follows an approximately normal distribution with $d f$ equal to the difference between the free parameters estimated in each of the models. If the difference between deviances in both models is not significant at 
$p<.05$, then the simplest model is selected to explain the matrix of responses to the BRCS.

To estimate the parameters of the Rasch models ConQuest v. 3.0 [30] was used, and for descriptive statistics and convergent validity we used SPSS v. 19.0.

\section{Item fit}

To assess the goodness of fit of the data to the Rasch model Conquest uses two statistics based on residuals of mean square (MNSQ). The unweighted mean square detect unexpected responses pattern when ability parameter is far to the item location parameter, while weighted mean square detect unexpected responses when ability parameter is very close to the item location parameter. An item shows a good fit to Rasch models if the unweighted or weighted item fit is found in the interval 0.6 to 1.4 [31].

\section{Reliability}

Conquest also provides a separability coefficient of the parameters that makes it possible to evaluate whether the localization parameters of the items are sufficiently separate to cover the whole interval of the ability. In this case, the parameters are separate enough if the reliability coefficient is equal to or higher than 0.90 or $\chi^{2}$ is significant.

\section{Unidimensionality and local independence}

In the Rasch model the items must form a unidimensional scale. Unidimensionality was tested with a principal components analysis (PCA) of residuals. It was considered that the BRCS was unidimensional if at least the first principal component explained a $50 \%$ of the variance and the eigenvalue was higher than 1.5. Local independence was examined with inter-item residual correlation matrix. The items were locally independent if inter-item residual correlations was lower than 0.70 .

\section{DIF}

DIF is evidence that the probabilities of the response of the groups can vary through the continuum of ability. Therefore, DIF exists if a group has a higher probability of offering an answer rather than another one systematically though all the levels of ability. In the present study DIF has been tested with regard to gender, a difference between male and female no greater than 0.50 has been taken as a criterion of non-DIF [32].

\section{Wright map}

A Wright map [27] allows ability parameters to be compared with item localization parameters on the BRCS in terms of logits. The Wright map to assess whether the calibration sample is appropriate for the group of items selected and has been useful or not. In both cases, this imbalance would cast doubt on the results of the calibration of the scale.

\section{Differences between groups}

After fitting the data to the Rasch model, the differences in resilience as regards gender, education and age interval were determined by Student's $t$ test or ANOVA, depending on the number of levels of each independent variable. Statistical significance was taken as $p<0.05$.

\section{Convergent validity}

To explore convergent validity we hypothesized that resilience would be higher among those SLE patients who have a greater quality of life, as shown by literature studies [33-35]. Subjects were first divided into 3 categories (low, moderate, high) using tertiles of HRQoL level as cut-off points. We then used ANOVA followed by the MSD post hoc test to compare mean scores from the BRCS across these 3 categories as a way to infer discriminant ability regarding HRQoL.

\section{Results}

Age, gender, disease duration, educational level and comorbidity with other illness in the sample appear in Table 1. The sample consisted of 232 cases $(88.2 \%$ females) who returned their postal survey, a response rate of $51.5 \%$. The average age was 48.6 years $(\mathrm{SD}=13.3)$

Table 1 Patients' characteristics $(N=232)$

\begin{tabular}{lll}
\hline & Mean (SD) & $\mathrm{N}(\%)$ \\
\hline Age (years) & $48.6(13.3)$ & \\
Disease duration (years) & $15.9(9.1)$ & \\
Gender & & \\
Female & & \\
Male & $302(88.2)$ \\
Education & \\
No schooling & $22(9.7)$ \\
Primary Education & $86(37.9)$ \\
Secondary Education & $75(33.0)$ \\
Higher Education & $44(19.4)$ \\
Comorbidity & \\
Osteoporosis & \\
Depression & $58(25.3)$ \\
Diabetes & $88(38.4)$ \\
Osteoarthritis & $23(10.0)$ \\
Anaemia & $63(27.5)$ \\
Peripheral vascular desease & $87(38.0)$ \\
Vertebral fractures & $60(26.2)$ \\
Kidney failure & $20(8.7)$ \\
Lung failure & $60(26.2)$ \\
\hline
\end{tabular}


Table 2 Frequencies(\%) distribution for each item of the Brief Resilient Coping Scale

\begin{tabular}{|c|c|c|c|c|}
\hline \multirow[b]{2}{*}{ Item } & \multicolumn{4}{|l|}{ Categories } \\
\hline & 0 & 1 & 2 & 3 \\
\hline I look for creative ways to alter difficult situations. & $19(8.3 \%)$ & $55(24.1 \%)$ & $78(34.2 \%)$ & $76(33.3 \%)$ \\
\hline Average score within category & 1.47 & 4.53 & 7.18 & 10.34 \\
\hline SD Score within category & 1.58 & 1.64 & 1.62 & 1.54 \\
\hline Regardless of what happens to me, I believe I can control my reaction to it. & $39(17.1 \%)$ & $69(30.3 \%)$ & $78(34.2 \%)$ & $42(18.4 \%)$ \\
\hline Average score within of category & 2.87 & 5.51 & 8.71 & 10.76 \\
\hline SD Score within of category & 2.03 & 1.86 & 1.64 & 1.56 \\
\hline I believe i can grow in positive ways by dealing with difficult situations & $28(12.3 \%)$ & $65(28.5 \%)$ & $82(35.9 \%)$ & $53(23.3 \%)$ \\
\hline Average score within of category & 2.00 & 5.38 & 7.83 & 10.85 \\
\hline SD Score within of category & 1.66 & 1.83 & 1.70 & 1.42 \\
\hline I actively look for ways to replace the losses I encounter in life. & $16(7.0 \%)$ & $49(21.5 \%)$ & $93(40.8 \%)$ & $70(30.7 \%)$ \\
\hline Average score within of category & 1.75 & 4.35 & 7.01 & 10.43 \\
\hline SD Score within of category & 2.24 & 1.83 & 1.87 & 1.57 \\
\hline
\end{tabular}

and the average duration of the illness was 15.9 years $(\mathrm{SD}=9.1)$.

\section{Ordering of categories}

Table 2 shows the mean and typical deviation of the item scores regarding the categories. The gradual increase of the means in each category signifies that the categories are well ordered and no unexpected violations have occurred.

\section{Which model is better?}

Which is the best model to explain the response matrix was tested by comparing deviance of PCM vs. RSM. Deviance for PCM was 1954.767 with $d f=13$, and for RSM was 1957.619 with $d f=7$. The difference was 2.852 $(d f=6)$, which was not statistically significant $(p>0.05)$. So, RSM was chosen as the most appropriate model for the BRCS. The location parameters appear in Table 3.

As expected from a scale constructed based on the classic test model, the four items had high homogeneity
(0.83 to 0.87 ) and the localization parameters were very close to the mean resilience of the sample used during the study. Items 2 and 3 were indicative of high resilience, while items 1 and 4 were below average parameters. The thresholds between categories were in order and sufficiently separated, indicating that they fulfilled their expected function of representing the degree of resilience in this sample, as shown in the Wright map (Fig. 1).

\section{Item fit}

Both the unweighted and weighted mean square for the items and the categories were in the specified interval $[0.6,1.4]$, so it is safe to say that the responses on the BRCS scale follow the RSM (Table 3).

\section{Separation reliability coefficient}

The separation coefficient of the parameters was .98 $\left(\chi^{2}=112.3, d f=3, p<0.001\right)$, which indicates that the thresholds of the four items were able to cover the

Table 3 Parameters of location and fitting statistics for the items and thresholds parameters of the Brief Resilient Coping Scale

\begin{tabular}{|c|c|c|c|c|c|c|c|c|c|}
\hline \multirow[b]{2}{*}{ Item } & \multirow[b]{2}{*}{ Location parameter } & \multirow[b]{2}{*}{ Standard error } & \multirow[b]{2}{*}{$\mathrm{R}_{\mathrm{jX}}$} & \multicolumn{3}{|c|}{ Unweighted fit } & \multicolumn{3}{|c|}{ Weighted fit } \\
\hline & & & & MNSQ & $\mathrm{Cl}$ & $\mathrm{T}$ & MNSQ & $\mathrm{Cl}$ & $\mathrm{T}$ \\
\hline 1 & -0.431 & 0.082 & .87 & 0.87 & {$[0.82,1.18]$} & -1.4 & 0.95 & [0.81-1.19] & -0.6 \\
\hline 2 & 0.706 & 0.081 & .83 & 1.11 & {$[0.82,1.18]$} & 1.2 & 1.09 & {$[0.82,1.18]$} & 0.9 \\
\hline 3 & 0.237 & 0.081 & .85 & 0.94 & {$[0.82,1.18]$} & -0.6 & 0.96 & {$[0.82,1.18]$} & -0.5 \\
\hline 4 & $-0.512^{a}$ & 0.141 & .83 & 0.98 & {$[0.82,1.18]$} & -0.1 & 1.01 & {$[0.81,1.19]$} & 0.1 \\
\hline \multicolumn{10}{|c|}{ Categories } \\
\hline 0 & & & & 0.94 & {$[0.82,1.18]$} & -0.7 & 1.11 & {$[0.70,1.30]$} & 0.7 \\
\hline 1 & -2.30 & 0.083 & & 1.24 & {$[0.82,1.18]$} & 2.4 & 1.23 & {$[0.80,1.20]$} & 2.1 \\
\hline 2 & -0.81 & 0.077 & & 1.25 & {$[0.82,1.18]$} & 2.5 & 1.27 & {$[0.82,1.18]$} & 2.7 \\
\hline 3 & $2.39^{a}$ & & & 1.12 & {$[0.82,1.18]$} & 1.3 & 1.16 & {$[0.77,1.23]$} & 1.3 \\
\hline
\end{tabular}

Notes: ${ }^{a}$ the parameter is constrained, $R_{j X}$ item-test corrected correlation, MNSQ Mean square, $C I$ Confidence Interval, $T$ Transformation Wilson-Hilferty 


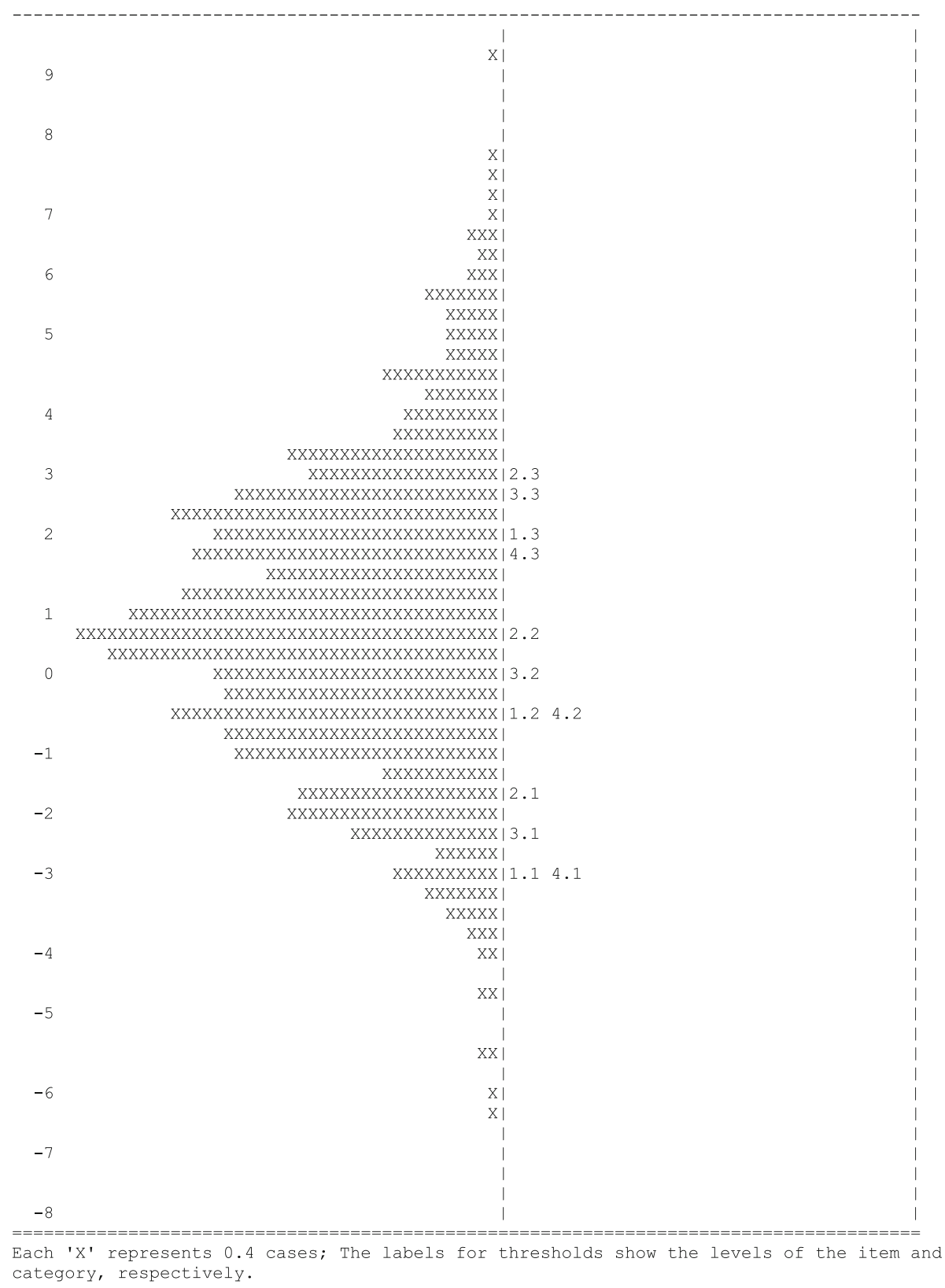

Fig. 1 Wright map for BRCS

interval of resilience of the sample in which the scale was calibrated, in spite of the small number of items of the BRCS.

\section{Dimensionality and local independence}

Dimensionality of the BRCS was tested with a residual PCA. The small number of items of the scale prevented the first factor from obtaining the expected salience as in other larger scales, but the first main component explained $46.08 \%$ of total variance (eigenvalue $=1.843$ ) so the scale was considered to be essentially unidimensional.
Local independence was obtained through correlations of the standardised residuals of the items which varied between -0.06 and -0.49 , never reaching the limit of 0.70 , so that the responses to the items were also considered to be locally independent.

\section{DIF}

The difference between males and females in the localization parameters of the four items was 0.11, never surpassing 0.50 , so DIF was not significant for any item. 


\section{Differences between groups}

After fitting the BRCS to RSM, the resilience parameters for the sample were estimated. No significant differences were found with respect to gender or age interval, but marginally significant differences $(p=.061)$ were found between educational levels, the mean of the resilience parameters increasing with educational level. Thus, the group of patients who had only studied primary education obtained a mean of resilience of $0.146(\mathrm{SD}=2.69)$, while those who had received higher education obtained a mean of $1.307(\mathrm{SD}=2.40)$ (Table 4$)$.

\section{Convergent validity}

Table 5 presents the BRCS scores by HRQoL level. Scores increased significantly with increasing either EQ$5 \mathrm{D}$ or EQ-VAS levels. The mean score obtained by the group of patients with a high level of EQ-VAS (60.2 to 100) was 69.7 , which is $39.4 \%$ per cent higher than the low-level category $(p<0.001)$, these differences were also observed when comparison between extreme groups was made using the "utility" values obtained by means of EQ-5D (41.2 \%) providing, in both cases, evidence of the construct validity of the BRCS.

\section{Discussion}

This is the first study that gives evidence of the reliability and validity of the BCRS using Rasch analysis, in a sample of patients with SLE. Good support was established for the psychometric properties of the BRCS with a good fit to the RSM, and no DIF was found. There was good internal consistency and support for the unidimensionality and local independence of the items on the scale. These results are in agreement with other produced with classical test theory [19-21].

The studies made to date in which resilient coping has been studied in patients with SLE have used the resilience

Table 4 Differences between groups (Student's t /ANOVA)

\begin{tabular}{|c|c|c|c|c|}
\hline & Mean (SD) & $t / F$ & $d f$ & $P$ \\
\hline \multicolumn{5}{|l|}{ Gender } \\
\hline Male & $1.28(2.07)$ & 1.10 & 226 & 0.271 \\
\hline Female & $0.74(2.39)$ & & & \\
\hline \multicolumn{5}{|l|}{ Educational level } \\
\hline No schooling & $0.15(2.69)$ & 2.50 & $(3,226)$ & $0.061^{\mathrm{a}}$ \\
\hline Primary education & $0.40(2.40)$ & & & \\
\hline Secundary education & $1.01(2.08)$ & & & \\
\hline Higher education & $1.31(2.40)$ & & & \\
\hline \multicolumn{5}{|l|}{ Age Interval } \\
\hline 1 (<45 años) & $0.93(2.36)$ & .22 & $(2,226)$ & 0.800 \\
\hline 2 (45-65 años) & $0.75(2.22)$ & & & \\
\hline 3 (>65 años) & $0.63(2.70)$ & & & \\
\hline
\end{tabular}

Marginally significant
Table 5 Convergent validity of the Brief Resilient Scale (BRCS) regarding HRQol (Euroqol test) ${ }^{a}$

\begin{tabular}{|c|c|c|}
\hline & \multicolumn{2}{|c|}{ BRCS Scores } \\
\hline & $\mathrm{n}$ & Mean [0-100] (Cl $95 \%)$ \\
\hline \multicolumn{3}{|c|}{ EQ visual analogue scale (EQ-VAS)Tertiles } \\
\hline Low $(\mathrm{T} 1)[\leq 40.0]$ & 75 & $50.9(45.2-56.6)$ \\
\hline Moderate (T2) [40.1-60.1] & 66 & $60.1(54.1-66.1)$ \\
\hline High (T3) [60.2-100.0] & 69 & $69.7(62.9-76.5)$ \\
\hline Overall mean & 210 & $60.0(56.3-63.7)$ \\
\hline \multicolumn{3}{|l|}{ EQ-5D descriptive system Tertiles } \\
\hline Low $(\mathrm{T} 1)[\leq 0.08]$ & 75 & $49.1(43.5-54.7)$ \\
\hline Moderate (T2) [0.08-0.31] & 77 & $60.2(54.2-66.2)$ \\
\hline High (T3) [0.32-1.00] & 73 & $69.5(63.3-75.7)$ \\
\hline Overall mean & 225 & $59.5(55.9-63.1)$ \\
\hline
\end{tabular}

${ }^{a}$ One-way analysis of variance followed by post hoc test. EQ EuroQol, EQ-VAS: Ho: $\mathrm{T} 1$ vs $\mathrm{T} 2=>p=0.03 ; \mathrm{Ho}: \mathrm{T} 1$ vs $\mathrm{T} 3=><0.001: \mathrm{Ho}: \mathrm{T} 2$ vs $\mathrm{T} 3=>p=0.03$. EQ-5D: Ho: $\mathrm{T} 1$ vs $\mathrm{T} 2=>p=0.009 ; \mathrm{Ho}: \mathrm{T} 1$ vs $\mathrm{T} 3=><0.001: \mathrm{Ho}: \mathrm{T} 2$ vs $\mathrm{T} 3=>p=0.02$

scale (RS) [36, 37]. This scale has 25 items and was developed for the general population. However, the brevity of the BCRS allows it to be completed quickly and easily by patients with conditions such as SLE, and that it can be administered multiple times in longitudinal studies as well as in large surveys. Validation of this scale using the Rasch model also points to its potential usefulness in daily clinical practice in patients with systematic erythematosus lupus.

Study of the dimensionality showed that the BRCS forms a unidimensional scale with localization parameters of the items and thresholds of the categories which clearly separate the resilience of the evaluated patients. There was no evidence of local dependence in the answers to the items.

This scale reflects one of the patterns of resilience, more specifically the situational pattern, which corresponds to resilient coping patterns [10]. Items in this measure refer to tenacity, optimism, creativity, and aggressive approach to problem solving, and commitment to positive growth from difficult situations [19]. By administering this scale to the patients, we obtain information concerning the degree of resilience that each patient has, allowing individuals with low resilience to be identified who need interventions aimed at developing coping skills. In this way, patients who receive treatment will develop abilities to face stressing situations daily, lessening the possibility of a psychological crisis. In fact, in the study of Sinclair \& Wallston [19] where BRCS was validated in a sample of rheumatoid arthritis in the US, it was observed that resilient coping showed significant improvement after a cognitive-behavioral intervention designed to enhance adaptive coping, which indicates that levels of resilient coping can be improved. 
In addition the BRCS correlates with perceived health status in patients with SLE, providing evidence of its construct validity. If interventions to build resilient coping could be refined, then perhaps quality of life could be improved in this population with a stressful chronic condition. The improvement of the quality of life in an incurable chronic illness is a primary objective and very important for patients. It would be advisable to consider cognitive-behavioral interventions aimed at enhancing resilient coping as a no-pharmacological treatment important for patients with SLE. This recommendation has been suggested in a study with Parkinson's patients, where resilient coping is considered one of the determining factors of disability and quality of life [16].

The length of the scale, only 4 items, may be considered a limiting factor of the quality of the scores, although its brevity means it can be used in clinical contexts where patients might not answer other longer resilience scales ("short but sweet").

Future research will study the properties of the BRCS in other clinical samples with chronic (e.g., fibromyalgia, diabetes, atopic dermatitis) or degenerative disease (e.g., Parkinson's disease, Multiple sclerosis).

\section{Conclusions}

The BRCS is a suitable scale for measuring resilience in patients with SLE. This scale might be useful for clinicians can obtain information concerning the degree of resilience that each patient has, allowing individuals with low resilience to be identified who need interventions aimed at developing coping skills.

\section{Appendix}

Table 6 BRC scale

\begin{tabular}{|c|c|c|c|c|}
\hline \multicolumn{5}{|c|}{ Consider how well the following statements describe your behavior and actions } \\
\hline \multirow{2}{*}{$\begin{array}{l}\text { 1. I look for creative } \\
\text { ways to alter } \\
\text { difficult situations. }\end{array}$} & 0 & 1 & 2 & 3 \\
\hline & $\begin{array}{l}\text { Does not } \\
\text { describe } \\
\text { me at all }\end{array}$ & $\begin{array}{l}\text { Does not } \\
\text { describe } \\
\text { me }\end{array}$ & $\begin{array}{l}\text { Describes } \\
\text { me }\end{array}$ & $\begin{array}{l}\text { Describes } \\
\text { me very } \\
\text { well }\end{array}$ \\
\hline \multirow{2}{*}{$\begin{array}{l}\text { 2. Regardless of } \\
\text { what happens } \\
\text { to me, I believe } \\
\text { I can control my } \\
\text { reaction to it. }\end{array}$} & 0 & 1 & 2 & 4 \\
\hline & $\begin{array}{l}\text { Does not } \\
\text { describe } \\
\text { me at all }\end{array}$ & $\begin{array}{l}\text { Does not } \\
\text { describe } \\
\text { me }\end{array}$ & $\begin{array}{l}\text { Describes } \\
\text { me }\end{array}$ & $\begin{array}{l}\text { Describes } \\
\text { me very } \\
\text { well }\end{array}$ \\
\hline \multirow{2}{*}{$\begin{array}{l}\text { 3. I believe that I } \\
\text { can grow in positive } \\
\text { ways by dealing } \\
\text { with difficult } \\
\text { situations. }\end{array}$} & 0 & 1 & 2 & 3 \\
\hline & $\begin{array}{l}\text { Does not } \\
\text { describe } \\
\text { me at all }\end{array}$ & $\begin{array}{l}\text { Does not } \\
\text { describe } \\
\text { me }\end{array}$ & $\begin{array}{l}\text { Describes } \\
\text { me }\end{array}$ & $\begin{array}{l}\text { Describes } \\
\text { me very } \\
\text { well }\end{array}$ \\
\hline \multirow{2}{*}{$\begin{array}{l}\text { 4. I actively look for } \\
\text { ways to replace } \\
\text { the losses I } \\
\text { encounter in life. }\end{array}$} & 0 & 1 & 2 & 3 \\
\hline & $\begin{array}{l}\text { Does not } \\
\text { describe } \\
\text { me at all }\end{array}$ & $\begin{array}{l}\text { Does not } \\
\text { describe } \\
\text { me }\end{array}$ & $\begin{array}{l}\text { Describes } \\
\text { me }\end{array}$ & $\begin{array}{l}\text { Describes } \\
\text { me very } \\
\text { well }\end{array}$ \\
\hline
\end{tabular}

\section{Acknowledgements}

We would like to thank the patients with systemic lupus erythematosus who completed the questionnaires which enabled us to conduct the study.

\section{Funding}

Not applicable.

\section{Availability of data and material \\ Not applicable.}

\section{Authors' contributions}

JALP, ABMH and JJGC participated in conception and design, data analysis and interpretation, drafting and revising the manuscript. DJNV participated in acquisition of data and revising the manuscript. VGS and KAW participated in revising the manuscript. All authors approving the final version of the manuscript submitted for review and for publication.

\section{Competing interest}

The authors declare that they have no competing interests.

\section{Consent for publication}

Not applicable.

Ethics approval and consent to participate

The study conforms to the principles of the Declaration of Helsinki [24] and was approved by the Research Bioethics Committee of the University of Murcia (Spain) (ID 1204/2015; 4/11/2015).

\section{Author details}

'Department of Basic Psychology and Methodology, Faculty of Psychology, Campus of Espinardo, University of Murcia, 30100 Murcia, Spain. ${ }^{2}$ Department of Physical Therapy, University of Murcia, Murcia, Spain. ${ }^{3}$ Department of Public Health, University of Murcia, Murcia, Spain. ${ }^{4}$ Vanderbilt University, Nashville, USA.

Received: 24 December 2015 Accepted: 8 September 2016

Published online: 13 September 2016

\section{References}

1. Iverson GL. The Need for Psychological Services for Persons with Systemic Lupus Erythematosus. Rehabil Psychol. 1995;40(1):39-49.

2. Hale ED, Treharne GJ, Lyons AC, Norton Y, Mole S, Mitton DL, et al. "Joining the dots" for patients with systemic lupus erythematosus: personal perspectives of health care from a qualitative study. Ann Rheum Dis. 2006; 65:585-9.

3. Burckhardt CS, Archenholtz B, Bjelle A. Quality of life of women with systemic lupus erythematosus: a comparison with women with rheumatoid arthritis. J Rheumatol. 1993:20:977-81.

4. Jennekens FG, Kater $L$. The central nervous system in systemic lupus erythematosus. 1. Clinical syndromes: a literature investigation. Rheumatology (Oxford). 2002;41:605-18.

5. Seawell AH, Danoff-Burg S. Psychosocial research on systemic lupus erythematosus: a literature review. Lupus. 2004;13:891-9.

6. Segui J, Ramos-Casals M, García-Carrasco M, de Flores T, Cervera R, Valdés $M$, et al. Psychiatric and psychosocial disorders in patients with systemic lupus erythematosus: a longitudinal study of active and inactive stages of the disease. Lupus. 2000:9:584-8.

7. Petri M, Naqibuddin M, Carson KA, Wallace DJ, Weisman MH, Holliday SL, et al. Depression and cognitive impairment in newly diagnosed systemic lupus erythematosus. J Rheumatol. 2010;37(10):2032-8.

8. Dyer JG, McGuinness TM. Resilience: Analysis of the concept. Arch Psychiatr Nurs. 1996;10:276-82.

9. Bonanno GA, Wortman CB, Lehman DR, Tweed RG, Haring M, Sonnega J, et al. Resilience to loss and chronic grief: a prospective study from preloss to 18-months postloss. J Pers Soc Psychol. 2002;83(5):1150-64.

10. Masten AS. Ordinary magic-resilience processes in development. Am Psychol. 2001;56:227-38.

11. Davydov DM, Stewart R, Ritchie K, Chaudieu I. Resilience and mental health. Clin Psychol Rev. 2010;30:479-95. 
12. Braun A, Müller UA, Müller R, Leppert K, Schiel R. Structured treatment and teaching of patients with type 2 diabetes mellitus and impaired cognitive function-the DICOF trial. Diabetes Med. 2004;21:999-1006.

13. Hou WK, Law CC, Yin J, Fu YT. Resource loss, resource gain, and psychological resilience and dysfunction following cancer diagnosis: a growth mixture modeling approach. Health Psychol. 2010;5:484-95.

14. Aspinwall $L G, M a c N a m a r a ~ A$. Taking positive changes seriously: toward a positive psychology of cancer survivorship and resilience. Cancer. 2005;104:2549-56.

15. Schumacher A, Sauerland C, Silling G, Berdel WE, Stelljes M. Resilience in patients after allogeneic stem cell transplantation. Support Care Cancer. 2014;22:487-93

16. Robottom BJ, Gruber-Baldini AL, Anderson KE, Reich SG, Fishman PS, Weiner WJ, et al. What determines resilience in patients with Parkinson's disease? Parkinsonism Relat Disord. 2012:18:174-7.

17. Luthar SS, Cicchetti D. The construct of resilience: Implications for interventions and social policies. Dev Psychopathol. 2000;12:857-85.

18. Polk LV. Toward a middle-range theory of resilience. Adv Nurs Sci. 1997;19(3):1-13.

19. Sinclair VG, Wallston KA. The development and psychometric evaluation of the Brief Resilient Coping Scale. Assess. 2004;11(1):94-101.

20. Tomás JM, Meléndez JC, Sancho P, Mayordomo T. Adaptation and initial validation of the BRCS in an elderly Spanish sample. Eur J Psychol Assess. 2012;28(4):283-9.

21. Limonero JT, Tomás-Sábado J, Gómez-Romero MJ, Maté-Méndez J, Sinclair VG, Wallston KA, et al. Evidence for validity of the brief resilient coping scale in a young Spanish sample. Span J Psychol. 2014;17:E34.

22. De Ayala RJ. The theory and practice of Item Response Theory. New York: The Guilford Press; 2009

23. Hochberg MC. Updating the American College of Rheumatology revised criteria for the classification of Systemic Lupus Erythematosus [letter]. Arthritis Rheum. 1997;40:1725.

24. World Medical Association. Declaration of Helsinki. BMJ. 1996;313(7070): $1448-9$.

25. Hamashima C, Yoshida K. A study of the reliability of health state valuations in the Japanese EuroQol instrument. Environ Health Prev Med. 2001;6(3):189-91.

26. Wang S-L, Wu B, Zhu L-A, Leng L, Bucala R, Lu L-J. Construct and criterion validity of the Euro Qol-5D in patients with Systemic Lupus Erythematosus. Plos One. 2014;9(6):e9883.

27. Wright BD, Masters GN. Rating scale analysis. Chicago: Mesa Press; 1982.

28. Masters GN. A Rasch model for partial credit scoring. Psychometrika. 1982;47(2):149-74.

29. Andrich D. Rasch models for measurement. Newbury Park: Sage Publications; 1988

30. Wu ML, Adams RJ, Wilson MR, Haldane SA. AcerConquest v. 3.0.1. Generalised item response modelling software. Melbourne: ACER Press; 2007.

31. Wright BD, Linacre J, Gustafsson J, Martin-Lof P. Reasonable mean-square fit values. Rasch Meas Trans. 1994:8:370.

32. Wang W. Assessment of differential item functioning. J Appl Meas 2008;9(4):387-408

33. Erim Y, Kahraman Y, Vitinius F, Beckmann M, Kröncke S, Witzke O. Resilience and quality of life in 161 living kidney donors before nephrectomy and in the aftermath of donation: a naturalistic single center study. BMC Nephrol. 2015;16(1):164

34. Robottom BJ, Gruber-Baldini AL, Anderson KE, Reich SG, Fishman PS, Weiner WJ, et al. What determines resilience in patients with Parkinson's disease? Parkinsonim Relat Disord. 2015:18(2):174-7.

35. Schumacher A, Sauerland C, Silling G, Berdel WE, Stelljes M. Resilience in patients after allogeneic stem cell transplantation. Support Care Cancer. 2014;22(2):487-93.

36. Cal SR, Santiago MB. Resilience in systemic lupus erythemathosus. Psychol Health Med. 2013;18(5):558-63.

37. Faria DA, Revoredo LS, Vilar MJ, Chaves EM. Resilience and treatment adhesion in patients with systemic lupus erythematosus. Open Rheumatol $\mathrm{J}$. 2014;21(8):1-8

\section{Submit your next manuscript to BioMed Central and we will help you at every step:}

- We accept pre-submission inquiries

- Our selector tool helps you to find the most relevant journal

- We provide round the clock customer support

- Convenient online submission

- Thorough peer review

- Inclusion in PubMed and all major indexing services

- Maximum visibility for your research

Submit your manuscript at www.biomedcentral.com/submit

) Biomed Central 